\title{
Grey Relational Analysis on Influencing Factors of Highway Slope Safety in Ankang Mountain Area
}

\author{
Yiyun Yang \\ School of Electronic \& Information Engineering, Ankang University, Ankang 725000, China
}

Corresponding Author Email: yangyiyun@aku.edu.cn

https://doi.org/10.18280/ijsse.100518

Received: 9 May 2020

Accepted: 25 August 2020

\section{Keywords:}

high slope, slope stability, sensitivity analysis, grey relational analysis (GRA)

\begin{abstract}
In recent years, Ankang has witnessed frequent occurrence of collapses and other instability phenomena, which brought huge losses to urban and rural transportation, and agricultural production. Therefore, it is very important to research and analyze the stability of highway slopes in this area. This paper systematically explores the factors that affect slope safety, namely, slope height, slope angle, cohesive force, bulk density, internal friction angle, and crack depth, through grey relational analysis (GRA), using engineering analysis software and MATLAB. The stability of the high slope was further evaluated through sensitivity analysis. The results show that cohesive force and internal friction angle are the leading factors affecting slope stability, followed by crack depth, while slope angle, bulk density and slope height are not major influencing factors. The research results provide the basis for the protection and design of similar slopes in Ankang prefecture.
\end{abstract}

\section{INTRODUCTION}

Slopes, natural or artificial, are a basic kind of geological environment in engineering, and the most common form of engineering construction. The stability of slopes is threated by major geological disasters around the world, namely, earthquake, flood, and landslide and debris flow. The slope damage and collapse seriously endangers the safety of public property and personnel.

Many parts of China belong to mountainous regions with complex geological conditions. In the local highway network, a good portion of highways pass through mountains and hills, where the geological environment gradually deteriorates $[1,2]$. The numerous geological problems bring great difficulties to highway construction.

Amidst middle and low mountains, Southern Shaanxi has an elevation difference of $100-200 \mathrm{~m}$. In some places, the difference even surpasses $200 \mathrm{~m}$. Highway construction in this region is impeded by narrow valleys, fractured rock strata, and severe weathering. Over the years, high slope deformation and destruction are commonplace during road construction and artificial excavation, causing huge economic losses and disasters for railway and highway transportation, as well as urban and rural construction. Slope deformation and damage is a major hazard to the safety of highway and railway transportation, and arguably the most complex topic in road and geotechnical engineering $[3,4]$.

Sandwiched between the Qinling Mountains and Daba Mountain, Ankang, a prefecture in Southern Shaanxi, has a diverse topography, featuring high mountains, and deep gullies cut by streams [1]. The huge elevation difference of the undulating terrain leads to an obvious vertical difference in climate. Like that in other mountainous areas, highway construction in Ankang prefecture needs to cope with the challenge posed by the topographical diversity. During highway construction, the artificial high slope might deform or collapse due to the excavation. For example, on the Southern Xikang Highway, a 55m-high artificial slope was formed at K211 milestone after the mountain on the right side was excavated.

The Anshan Highway, which starts from Ankang and ends at the boundary between Shaanxi and Sichuan, passes through most of the areas between the Qinling Mountains and Daba Mountain, spanning two geomorphic units: middle and low mountains, and Hanjiang terraces. The topography along the highway is changeable, under the effects of rain erosion, weathering, etc. There are many high slopes, mostly along the banks of the Hanjiang River and Renhe River, with different types of rock along the highway, owing to the complex hydrogeology, topography, and geological conditions. Some of them are weak in rock quality, and highly weathered and fissured. Once excavated or saturated with water, the slopes will soften and lose stability, and become susceptible to landslide, collapse, and other adverse phenomena [3-5].

In recent years, Ankang prefecture has witnessed frequent occurrence of slope instabilities, such as landslide, collapse, and debris flow. The major landslides include the one hitting Maoping Town, Baihe County, and the multiple landslides occurring on June 18, 2010 in Qiyan Village, Dazhuyuan Town, Hanbin District, and Muzhu Village, Siji Town, Langao County. The landslides endanger driving safety, destroy farmland, incur huge losses to many sectors (e.g., urban and rural transportation, and agriculture), and bring heavy causalities. As a result, it is very important to study the stability of highway slopes in mountainous regions like Ankang prefecture.

Slope stability is affected by many internal and external factors. The internal factors include geological structure, geometric shape, and geotechnical features. The external factors include rainfall, reservoir water, earthquake, and engineering activities. The degree of impact of each factor determines the sliding mechanism and pattern of destruction. 
Principal component analysis (PCA) is an effective way to reveal the mechanism of each factor, and facilitate landslide control, monitoring and prediction $[6,7]$.

Owing to the interaction and uncertainty of the intricate factors $[8,9]$, the slope instability must be evaluated and treated by different methods that suit the actual situation $[10$, 11]. The relevant methods fall into quantification, qualification, and fuzzy calculation. Because the mechanical parameters required for quantification are random and uncertain, it is highly necessary to evaluate the effects of multiple physical-mechanical parameters in a comprehensive manner. This is made possible by the continuous improvement of computer technology.

Using engineering analysis software and MATLAB, this paper systematically investigates the factors that affect slope safety, namely, slope height, slope angle, cohesive force, bulk density, internal friction angle, and crack depth, through grey relational analysis (GRA), and thoroughly evaluates the stability of the high slope through sensitivity analysis.

\section{DAMAGE FORMS OF SLOPE INSTABILITY}

Natural or artificial slopes are either made of soil or rocks. It is a challenging task to maintain slope stability in highway construction, transportation, and port engineering [3]. The various defects in design and construction often cause the slope to collapse or slide. The slope instability exists in various forms, depending on the specific composition and structure of the slope $[12,13]$.

\subsection{Wedge type damage}

This is a common form of damage of rock slopes. When the slope is damaged, the rock mass is divided into wedges by multiple structural layers. Then, the slide mass moves along the intersection of the structural planes. The movement between two structural planes complicates the mechanical mechanism of slope failure.

\subsection{Toppling type damage}

This damage is often associated with the reverse layered structure of the slope. It could be further broken down into three types: bending toppling, block toppling, and block bending toppling. In nature, bending and inclined deformation is the combined result of these three kinds of toppling type damage.

\subsection{Plane type damage}

Plane type damage occurs as the slide mass moves inclinedly. In this case, the sliding surface is usually the structural plane formed in the slope, such as the rock layer and the weak layer between the structural layers. In engineering practice, most plane type damages are not typical $[14,15]$. The sliding surface of the slope tends to be a complex surface of two or more structural surfaces with different inclinations.

\subsection{Arc type damage}

Arc type damage usually takes place in weak slopes or the slopes with broken rock joints or abnormal rock development. Compared with the slope, the rock particles are so small as to be negligible. When there is no interaction between particles, the arc type damage will occur easily, if the rock mass is similar to the soil slope. The highly corroded and differentiated rocks also tend to suffer from arc type damage.

To sum up, slope instability varies with the complex and changeable slope structure and environment [16-19]. To evaluate slope safety, it is necessary to determine the damage pattern of the slope under the specific geological environment, and derive the slope stability coefficient by various calculation methods.

\section{INTERNAL FACTOR ANALYSIS}

Slope stability is affected by various factors. The main factors can be divided into internal factors and external factors. This chapter focuses on the internal factors, each of which has a unique influence on slope stability. Taking a rock slope of Anchuan Highway as the object, the stability factors were discussed based on the data of field investigation.

Most slopes along the target highway are rock slopes. In total, there are 119 rock slopes along the highway. Among them, 34 are less than $20 \mathrm{~m}$ tall, 66 are between 20 and $39 \mathrm{~m}$, and 19 are over $40 \mathrm{~m}$. The stability conditions of these rock slopes are summarized in Table 1. It can be seen that the rock slopes along the highway are generally stable, with a few with poor stability. Specifically, there are 22 highly stable slopes, 35 slightly stable ones, 24 slightly unstable ones, and 4 highly unstable ones, accounting for $24.71 \%, 41.18 \%, 28.24 \%$, and $5.88 \%$ of all slopes, respectively [1].

Table 1. The stability conditions of the rock slopes

\begin{tabular}{ccccc}
\hline $\begin{array}{c}\text { Stability } \\
\text { level }\end{array}$ & $\begin{array}{c}\text { Highly } \\
\text { stable }\end{array}$ & $\begin{array}{c}\text { Slightly } \\
\text { stable }\end{array}$ & $\begin{array}{c}\text { Slightly } \\
\text { unstable }\end{array}$ & $\begin{array}{c}\text { Strongly } \\
\text { unstable }\end{array}$ \\
\hline $\begin{array}{c}\text { Number of } \\
\text { slopes }\end{array}$ & 22 & 35 & 24 & 4 \\
\hline
\end{tabular}

The internal factors of slope stability include slope height, slope angle, cohesion, bulk density, internal friction angle, and crack depth. Table 2 lists the initial mechanical parameters of a rock slope on the target highway. The safety factor of the slope was calculated under the combined effect of multiple factors, using Lizheng Software and limit equilibrium method.

Table 2. The initial mechanical parameters of a rock slope

\begin{tabular}{cccccc}
\hline $\begin{array}{c}\text { Slope } \\
\text { height } \\
\boldsymbol{h} / \mathbf{m}\end{array}$ & $\begin{array}{c}\text { Slope } \\
\text { angle } \\
/ 0\end{array}$ & $\begin{array}{c}\text { Cohesive } \\
\text { Force } \\
\boldsymbol{c} / \mathbf{k P a}\end{array}$ & $\begin{array}{c}\text { Bulk } \\
\text { density / } \\
\left(\mathbf{k N} \cdot \mathbf{m}^{-3}\right)\end{array}$ & $\begin{array}{c}\text { Internal } \\
\text { friction } \\
\text { angle/ }\end{array}$ & $\begin{array}{c}\text { Crack } \\
\text { depth } \\
\boldsymbol{h}_{\boldsymbol{w}} / \mathbf{m}\end{array}$ \\
\hline 38.5 & 45 & 48.6 & 16 & 25 & 6.6 \\
\hline
\end{tabular}

\subsection{Influence of slope height}

The influence of slope height on safety factor was analyzed by changing the slope height, while fixing all the other factors. The analysis results are shown in Figure 1 and Table 3. It can be seen that the safety factor decreased exponentially with the growing slope height. 
Table 3. The safety factors under the effect of different factors

\begin{tabular}{|c|c|c|c|c|c|c|c|c|c|c|c|}
\hline $\begin{array}{c}\text { Slope } \\
\text { height } \\
h / \mathrm{m}\end{array}$ & $\begin{array}{l}\text { Safety } \\
\text { factor }\end{array}$ & $\begin{array}{c}\text { Slope } \\
\text { angle } \\
j\end{array}$ & $\begin{array}{l}\text { Safety } \\
\text { factor }\end{array}$ & $\begin{array}{l}\text { Cohesive } \\
\text { force } c / \mathbf{k P a}\end{array}$ & $\begin{array}{l}\text { Safety } \\
\text { factor }\end{array}$ & $\begin{array}{c}\text { Bulk } \\
\text { density / } \\
\left(\mathbf{k N} \cdot \mathbf{m}^{-3}\right)\end{array}$ & $\begin{array}{l}\text { Safety } \\
\text { factor }\end{array}$ & $\begin{array}{c}\text { Internal } \\
\text { friction } \\
\text { angle } /{ }^{\circ}\end{array}$ & $\begin{array}{l}\text { Safety } \\
\text { factor }\end{array}$ & $\begin{array}{l}\text { Crack } \\
\text { depth } \\
h_{w} / \mathbf{m} \\
\end{array}$ & $\begin{array}{l}\text { Safety } \\
\text { factor }\end{array}$ \\
\hline 30.5 & 1.651 & 45 & 1.487 & 28.6 & 1.071 & 12 & 1.611 & 15 & 1.059 & 2.6 & 1.095 \\
\hline 34.5 & 1.486 & 55 & 1.264 & 38.6 & 1.209 & 16 & 1.413 & 20 & 1.198 & 4.6 & 1.201 \\
\hline 38.5 & 1.347 & 60 & 1.201 & 48.6 & 1.347 & 20 & 1.294 & 25 & 1.347 & 6.6 & 1.301 \\
\hline 42.5 & 1.230 & 65 & 1.157 & 58.6 & 1.485 & 26 & 1.183 & 30 & 1.508 & 8.6 & 1.390 \\
\hline 50.5 & 1.047 & 75 & 1.084 & 68.6 & 1.623 & 34 & 1.095 & 35 & 1.687 & 10.6 & 1.467 \\
\hline
\end{tabular}

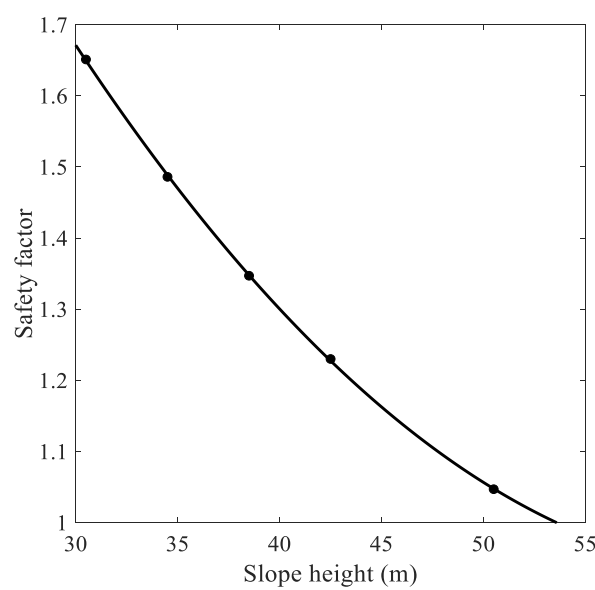

Figure 1. The curve of slope height and safety factor

\subsection{Influence of internal friction angle}

The influence of internal friction angle on safety factor was analyzed by changing the angle from $15^{\circ}$ to $35^{\circ}$, while fixing all the other factors. The analysis results are shown in Figure 2 and Table 3. It can be seen that the safety factor is sensitive to the internal friction angle: the factor increased linearly with the growth in internal friction angle.

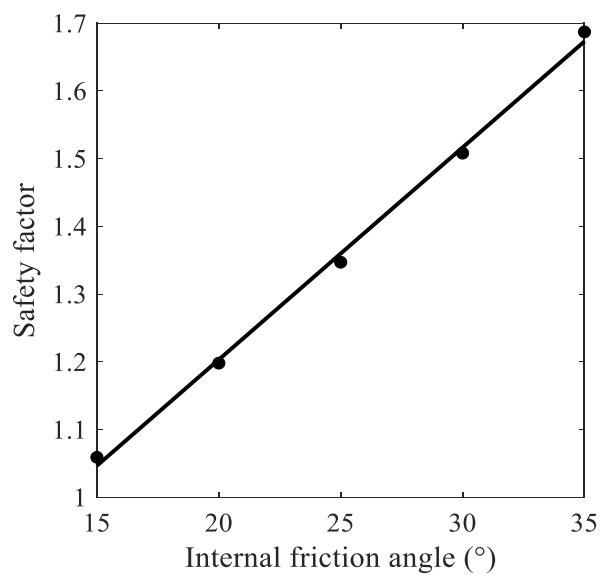

Figure 2. The curve of internal friction angle and safety factor

\subsection{Influence of bulk density}

The influence of bulk density on safety factor was analyzed by changing the bulk density from 12 to $34 \mathrm{kPa}$, while fixing all the other factors. The analysis results are shown in Figure 3 and Table 3. It can be seen that the safety factor decreased exponentially with the growing bulk density, similar to the change law with the growing slope height.

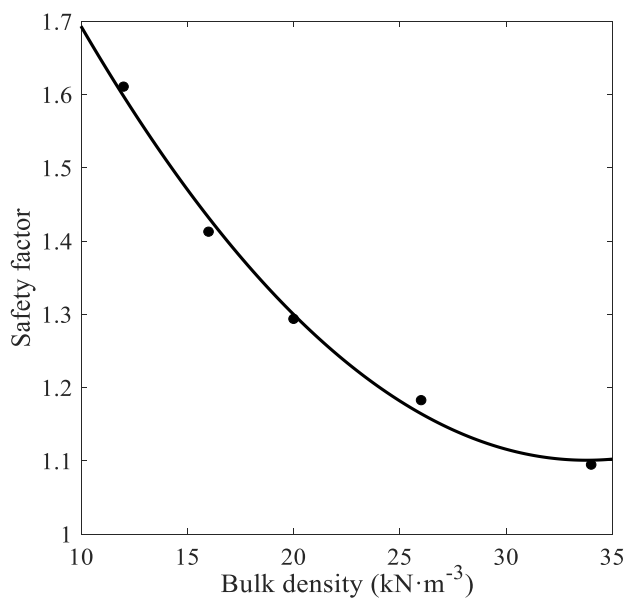

Figure 3. The curve of bulk density and safety factor

\subsection{Influence of cohesive force, slope angle, and crack depth}

Similarly, the safety factors under the effect of cohesive force, slope angle, and crack depth was calculated separately. Among them, the crack depth refers to the distance from the water level to the top of the slope. As shown in Table 3, the safety factor increased as the cohesive force rose from 28.6 to $68.6 \mathrm{kPa}$, gradually decreased as the slope angle expanded from $45^{\circ}$ to $75^{\circ}$, and increased as the crack depth extended from 2.6 to $10.6 \mathrm{~m}$.

The relationship between safety factor and crack depth is attributable to the following facts. Many engineering evidences show that most landslides occur under the influence of water. That is, water is a key impactor of slope stability. Along the Anchuan Highway, many rock slopes are close to rivers. Thus, the groundwater level is high in these slopes, especially during the rainy season. When the rock mass is saturated with river water, the slide surface of the slope will become unstable, sowing the seeds of landslide. That is why the safety factor increases with the crack depth. After all, the rising local water level weakens the shear strength of the slope [2].

\section{GRA}

\subsection{Grey theory}

Proposed by Deng Julong in 1982, the grey system theory (GST) [6] is the primary method for analyzing uncertain problems. The GST extracts a small amount of data to predict the law of parameter change. One of the basic GST methods is the GRA, which is simple and easy to operate. It is a practical method to study slope stability. 
(1) Parameter selection

The various factors affecting slope stability, such as internal friction angle, cohesive force, density, and crack depth were compiled into a subsequence of matrix $\mathrm{M}$ :

$$
M=\left[\begin{array}{c}
M_{1} \\
M_{2} \\
\vdots \\
M_{i}
\end{array}\right]=\left[\begin{array}{cccc}
m_{11} & m_{12} & \ldots & m_{1 j} \\
m_{21} & m_{22} & \ldots & m_{2 j} \\
\vdots & \vdots & \ddots & \vdots \\
m_{i 1} & m_{i 2} & \ldots & m_{i j}
\end{array}\right]
$$

where, $m_{i j}$ is the value of the $i$ factor. The safety factor under the effect of a factor in matrix $\mathrm{M}$ was taken as the parent sequence $\mathrm{N}$ :

$$
N=\left[\begin{array}{c}
N_{1} \\
N_{2} \\
\vdots \\
N_{i}
\end{array}\right]=\left[\begin{array}{cccc}
n_{11} & n_{12} & \ldots & n_{1 j} \\
n_{21} & n_{22} & \ldots & n_{2 j} \\
\vdots & \vdots & \ddots & \vdots \\
n_{i 1} & n_{i 2} & \ldots & n_{i j}
\end{array}\right]
$$

where, $n_{i j}$ is the safety factor $\mathrm{j}$ under the effect of the $i$ factor.

(2) Range variation

The range variation of each factor was performed to eliminate the effect of factor dimensions on the parent sequence $N$ and sub-sequence $M$ :

$$
m_{i j}^{\prime}=\frac{m_{i j}-\min m_{i j}}{\max m_{i j}-\min m_{i j}}
$$

After the range variation, the differential sequence matrix was derived from sequences $N$ and $M$ :

$$
\Delta_{i j}=\left|m_{i j}-n_{i j}\right|
$$

(3) Correlation calculation

To calculate the correlation degree $g_{i}$, the incidence matrix $L$ was introduced, whose element can be expressed as:

$$
l_{i j}=\frac{\Delta_{\min }+\eta \Delta_{\max }}{\Delta_{i j}+\eta \Delta_{\max }}
$$

where, $\eta \in(0,1)$. is the corresponding discriminant coefficient. The correlation degree reflects the similarity between a subsequence and the parent sequence. Theoretically, the value range of the correlation degree is $[0,1]$. If the degree is close to one, the greater the correlation degree, the higher the sensitivity of the subsequence; If the degree is close to zero, the subsequence is not similar to the parent sequence. The correlation degree $g_{i}$ can be calculated by:

$$
g_{i}=\frac{1}{k} \sum_{j=1}^{k} l_{i j}
$$

where, $k$ is the number of influencing factors.

\subsection{Sensitivity analysis}

According to Table 3, $\mathrm{M}$ and $\mathrm{N}$ can be respectively set up

$$
\begin{aligned}
M & =\left[\begin{array}{l}
\alpha \\
h_{w} \\
\varphi \\
\gamma \\
c \\
h
\end{array}\right]=\left[\begin{array}{lllll}
75 & 65 & 60 & 55 & 45 \\
10.6 & 8.6 & 6.6 & 4.6 & 2.6 \\
35 & 30 & 25 & 20 & 15 \\
34 & 26 & 20 & 16 & 12 \\
68.6 & 58.6 & 48.6 & 38.6 & 28.6 \\
50.5 & 42.5 & 38.5 & 34.5 & 30.5
\end{array}\right] \\
N & =\left[\begin{array}{llllll}
1.084 & 1.157 & 1.201 & 1.264 & 1.487 \\
1.467 & 1.390 & 1.301 & 1.201 & 1.095 \\
1.687 & 1.508 & 1.347 & 1.198 & 1.059 \\
1.095 & 1.183 & 1.294 & 1.413 & 1.611 \\
1.623 & 1.485 & 1.347 & 1.209 & 1.071 \\
1.047 & 1.230 & 1.347 & 1.486 & 1.651
\end{array}\right]
\end{aligned}
$$

Executing formulas (1) and (2) on MATLAB, the differential sequence matrix can be obtained:

$$
\Delta=\left[\begin{array}{ccccc}
1.000 & 0.486 & 0.210 & 0.113 & 1.000 \\
0.000 & 0.043 & 0.054 & 0.035 & 0.000 \\
0.000 & 0.035 & 0.041 & 0.029 & 0.000 \\
1.000 & 0.466 & 0.022 & 0.435 & 1.000 \\
0.000 & 0.000 & 0.000 & 0.000 & 0.000 \\
1.000 & 0.297 & 0.097 & 0.529 & 1.000
\end{array}\right]
$$

Executing formula (3) on MATLAB, the correlation coefficient matrix can be obtained:

$$
L=\left[\begin{array}{lllll}
0.333 & 0.507 & 0.705 & 0.815 & 0.333 \\
1.000 & 0.921 & 0.903 & 0.935 & 1.000 \\
1.000 & 0.935 & 0.924 & 0.949 & 1.000 \\
0.333 & 0.518 & 0.958 & 0.535 & 0.333 \\
1.000 & 1.000 & 1.000 & 1.000 & 1.000 \\
0.333 & 0.627 & 0.838 & 0.487 & 0.333
\end{array}\right]
$$

According to the above results and formula (4), the correlation degree $G$ can be obtained:

$$
\begin{aligned}
& G=\left[\begin{array}{llllll}
\alpha & h_{w} & \varphi & \gamma & c & h
\end{array}\right]^{\mathrm{T}} \\
& =\left[\begin{array}{llllll}
0.539 & 0.952 & 0.961 & 0.535 & 1.000 & 0.524
\end{array}\right]^{T}
\end{aligned}
$$

Through the above calculation, the correlation degree $g_{i}$ of each parameter was sorted. For the slope sensitivity of Anchuan highway, the correlation sequence can be obtained as: $c>\varphi>h_{w}>\alpha>\gamma>h$. Obviously, cohesive force and internal friction angle are the leading influencing factors of slope stability. By contrast, slope stability is not sensitive to slope height and bulk density.

The above results are similar to the findings of Zhao et al. [20] the influencing factors of slope stability can be ranked in descending order of impact as cohesive force, internal friction angle, severity, seismic action, slope height and slope rate. Their findings were obtained through a GCA on a loess slope in Yuzhong County, Lanzhou. 


\section{PROTECTIVE MEASURES FOR SLOPE STABILITY}

Slope reinforcement should consider the basic features of slope deformation and damage. As mentioned before, the failure pattern of slope is very complicated. It could be affected by geological conditions, construction method, hydrology, and climate [21]. At present, there is no widely accepted method to judge the damage forms of slope. Consequently, most projects design slope reinforcement based on engineering experience and calculation under the specific geological and geomorphic conditions.

The investigation and above analysis show that the rock slopes along Anchuan Highway are generally stable, but some of them face potential risk of losing stability. Based on the research results, several reasonable and economical protective measures were put forward for different types of rock slopes.

(1) The relatively stable rock slopes, which are slightly weathered and fragmented, should be protected by diamond or square grass planting. Using planting bags, grass planting can protect the entire slope without breaking the surface.

(2) The relatively stable rock slopes, which are strongly weathered and fragmented, should be protected by safety netting system (SNS). Rocks might fall from these slopes, and disrupt the normal driving on the highway. The SNS is an advanced slope protection system with low construction risk and low labor intensity. It can effectively stabilize the rock mass, and prevent it from displacement [1]. Moreover, the SNS can integrate different slope greening methods, and beautify the slope surface, creating a good environment.

(3) The unstable rock slopes should be protected by bolt frame beam and grass planting. This technology can control the instability of the rock slope, ensure the safety of vehicles on the highway, and green the slope and the surroundings. The protective system is easy to construct and neat in appearance. The entire slope can be greeted by flexibly adjusting the planting bags in the frame, number of bolts, anchoring depth, and anchorage force.

(4) The unstable mudstone slopes should be protected by arch framework. Because of the special stress feature of the arch structure, concrete arch skeleton outshines the other shapes (e.g., diamond, and square) in slope protection. With a beautiful design, the arch framework can afforest the slope, prevent soil erosion, and curb further weathering of the bedrock. The advantages of this technology also include simple laying and pouring, ease of transportation, compatibility with various slopes and shapes, and high environmental applicability. However,

However, it is very difficult to anchor the planting bag on the high slope without the concrete skeleton, and the bags must be of high quality.

(5) The severely weathered and near-collapse slopes should be protected by anti-slide piles, which can be constructed easily in a short time, without greatly disturbing the slide mass [3-5]. The pile parameters (e.g., position, length, and sectional area) can be flexibly adjusted as per the field condition.

\section{CONCLUSIONS}

Owing to topography and landform features, slope stability is affected by various factors. It is important to identify the leading factors before designing the protective measures. This paper theoretically analyzes the main factors affecting the safety factor of the rock slopes along a highway, including, cohesive force, internal friction angle, crack depth, slope angle, bulk density, and slope height. The relationship between each factor and the safety factor was derived, and the specific impact of each factor was clarified in turn. On this basis, the GRA was introduced to rank the factors by the correlation degree with slope safety. The ranking reveals the leading influencing factors of slope stability, namely, cohesive force and internal friction angle, and the sensitivity of slope stability to each factor. Next, several reasonable and economical protective measures were put forward for different types of rock slopes. The research results provide a reference for protecting similar slopes and improving the environment in Ankang prefecture.

\section{ACKNOWLEDGMENT}

The work is supported by Ankang Science and Technology Research and Development Program (Grant No.: AK2019SF09), and Scientific Research Fund of Shaanxi Provincial Department of Education (Grant No.: 19JK0012).

\section{REFERENCES}

[1] Lu, J.H. (2016). Research on stability analysis and protection technology of Anchuan highway high slope. $\mathrm{Xi}$ 'an: Chang 'an University, 2016: 2-32. https://doi.org/10.7666/d.D01115157

[2] Guo, F., Liang, Z.Z., Gong, B., Li, G. (2017). Tensile failure in slope stability analysis of geotechnical engineering. Journal of rock mechanics and engineering, 2017(s1):

https://doi.org/10.13722/j.cnki.jrme.2016.0674

[3] Li, J. (2015). Slope stability analysis and design of antislide pile. Hefei: Hefei University of Technology, 2015: 1-25. https://doi.org/10.7666/d.Y2913112

[4] Hou, X.M., Yang, Z.S. (2017). Stability analysis and treatment design selection of high fill slope in low mountain and hilly area. West-China Exploration Engineering, $29(7)$ : $20-24,2$ https://doi.org/10.3969/j.issn.1004-5716.2017.07.007

[5] Zhang, A.Q. (2017). The Study of Stability of Soil Slope under Stream Erosion. Harbin: Northeast Agricultural University, 2017: 2-30.

[6] Dai, T.D. (2015). Research on the stability of road slope in complex environment. Nanjing: Southeast University, 2015: 5-24. https://doi.org/10.7666/d.Y2781714

[7] Yang, P.L. (2017). Research on protection of high and steep rocky slope at the left bank of Jinfoshan Reservoir in Chongqing. Chongqing: Chongqing Jiaotong University, 2017: 3-27.

[8] Li, Y.Z. (2016). The Protection and Management of Gravel Soil Slope with Crib Grille in Tibet Area. Xi 'an: Chang 'an University, 2016: 1-18. https://doi.org/10.7666/d.D01113925

[9] Sun, M.F. (2016). Stability analysis and protection measures of the Heng'er road in the new area between Guiyang and Anshun. Huai'an: Anhui University of Science and Technology, 2016: 1-13. https://doi.org/10.7666/d.Y3010513

[10] Griffiths, D.V., Lane, P.A. (1999). Slope stability analysis by finite elements. Geotechnique, 49(3): 387403. https://doi.org/10.1680/geot.1999.49.3.387 
[11] Keefer, D.K. (1994). The importance of earthquakeinduced landslides to long-term slope erosion and slopefailure hazards in seismically active regions. In Geomorphology and Natural Hazards, 1994: 10:265-284. https://doi.org/10.1016/B978-0-444-82012-9.50022-0

[12] Manzari, M.T., Nour, M.A. (2000). Significance of soil dilatancy in slope stability analysis. Journal of Geotechnical and Geoenvironmental Engineering, 126(1): 75-80.

[13] Griffiths, D.V., Lane, P.A. (1999). Slope stability analysis by finite elements. Geotechnique, 49(3): 387403. https://doi.org/10.1680/geot.1999.49.3.387

[14] Ugai, K. (1989). A method of calculation of total factor of safety of slopes by elastic-plastic FEM. Soils Found, 29(2): 190-195.

[15] Duncan, J.M. (1996). State of the art: limit equilibrium and finite-element analysis of slopes. Journal of Geotechnical Engineering, 122(7): 577-596.

[16] Zienkiewicz, O.C., Humpheson, C., Lewis, R.W. (1975). Associated and non-associated visco-plasticity and plasticity in soil mechanics. Geotechnique, 25(4): 671689. https://doi.org/10.1680/geot.1975.25.4.671
[17] Sarma, S.K. (1979). Stability analysis of embankments and slopes. Journal of Geotechnical and Geoenvironmental Engineering, 105(ASCE 15068). http://worldcat.org/oclc/3519342

[18] Hoek, E., Bray, J.W., Boyd, J.M. (1973). The stability of a rock slope containing a wedge resting on two intersecting discontinuities. Quarterly Journal of Engineering Geology and Hydrogeology, 6(1): 1-55. https://doi.org/10.1144/GSL.QJEG.1973.006.01.01

[19] Revilla, J., Castillo, E. (1977). The calculus of variations applied to stability of slopes. Geotechnique, 27(1): 1-11. https://doi.org/10.1680/geot.1977.27.1.1

[20] Zhao, Y.H., Liu, G., Mao, J., Chen, L.F., Wei, M.E. (2015). Sensitivity analysis for the stability of loess slope based on grey correlation degree. Journal of Yangtze River Scientific Research Institute, 32(7): 94-98. https://doi.org/10.3969/j.issn.1001-5485.2015.07.017

[21] Ren, Z.H. (2005). The Stability analysis and protection designing for high side slope of superhighway in mountainous area. Kunming: Kunming University of Science and Technology, 2005: 5-45. 